
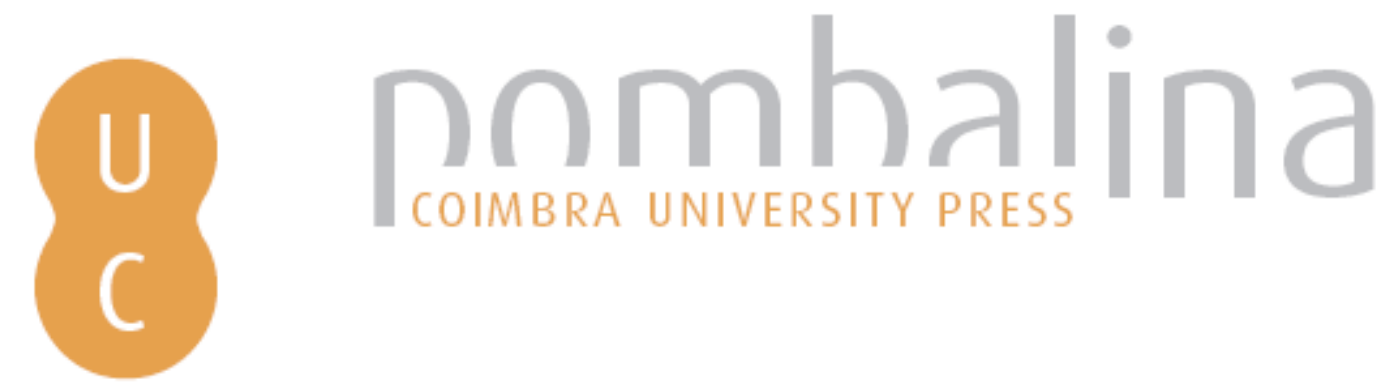

\title{
De la villa a la ecclesia (I): los documentos literarios sobre las transformaciones religiosas en la Hispania rural
}

\author{
Autor(es): $\quad$ Sanz Serrano, Rosa \\ Publicado por: Imprensa da Universidade de Coimbra \\ URL \\ persistente: URI:http://hdl.handle.net/10316.2/42126 \\ DOI: $\quad$ DOI:https://doi.org/10.14195/978-989-26-1353-6_13 \\ Accessed : $\quad$ 26-Apr-2023 10:37:30
}

A navegação consulta e descarregamento dos títulos inseridos nas Bibliotecas Digitais UC Digitalis, UC Pombalina e UC Impactum, pressupõem a aceitação plena e sem reservas dos Termos e Condições de Uso destas Bibliotecas Digitais, disponíveis em https://digitalis.uc.pt/pt-pt/termos.

Conforme exposto nos referidos Termos e Condições de Uso, o descarregamento de títulos de acesso restrito requer uma licença válida de autorização devendo o utilizador aceder ao(s) documento(s) a partir de um endereço de IP da instituição detentora da supramencionada licença.

Ao utilizador é apenas permitido o descarregamento para uso pessoal, pelo que o emprego do(s) título(s) descarregado(s) para outro fim, designadamente comercial, carece de autorização do respetivo autor ou editor da obra.

Na medida em que todas as obras da UC Digitalis se encontram protegidas pelo Código do Direito de Autor e Direitos Conexos e demais legislação aplicável, toda a cópia, parcial ou total, deste documento, nos casos em que é legalmente admitida, deverá conter ou fazer-se acompanhar por este aviso.

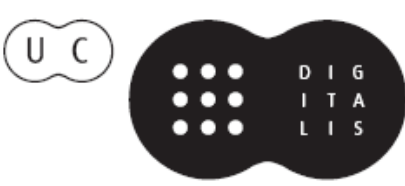




\section{Arqueologia \\ da transição:}

entre o mundo romano

e a Idade Média

Cláudia Teixeira, André Carneiro (coords.)

IMPRENSA DA UNIVERSIDADE DE COIMBRA

ANNABLUME 


\title{
DE LA VILLA A LA ECCLESLA (I): Los DOCUMENTOS Literarios SOBRE LAS TRANSFORMACIONES RELIGIOSAS EN LA HISPANIA RURAL (From villa to ecclesia (I): literary testimonies on the religious transformations in rural Hispania)
}

\author{
Rosa Sanz Serrano \\ Dpto Historia Antigua - UCM
}

\begin{abstract}
Resumo - A estrutura de povoamento peninsular transforma-se de modo significativo durante a Antiguidade Tardia. A leitura da documentação permite detetar alterações nos modos de designação dos sítios, em especial com o surgimento de termos neutros, como villula. Estas mudanças serão debatidas em seguida.
\end{abstract}

Palavras-chave - Villa, villula, cristianismo antigo, estruturas de povoamento.

Aвstract - During Late Antiquity, the iberian settlement patterns changes dramatically. Reading the written sources, we can see the phenomena of change in the way as places are mentionned, emerging neutral designations. These changes will be discussed in this paper.

KEYwords - Villa, villula, ancient christianity, settlement patterns.

Existe en la actualidad un interés cada vez mayor por el estudio de la transformación de los espacios religiosos en las Hispanias a partir del s. Iv. Lamentablemente, en el análisis histórico de los cambios estructurales y materiales, el debate ha dado excesiva importancia a la llamada por el historiador Orosio "pérdida de las Hispanias" a raíz de la usurpación de Constantino III en la Prefectura de la Galia y de la llegada en el año 409 de suevos, vándalos y alanos ${ }^{1}$. Y lo ha hecho a pesar de la pobreza de fuentes escritas y de su evidente intencionalidad, sobre todo en el caso del obispo Hidacio cuando atribuye a los bárbaros las destrucciones de centros cristianos en el norte peninsular y evita cualquier información sobre los centros de culto pagano y la política imperial de persecución religiosa.

Como consecuencia de la lectura sesgada, tanto arqueológica como literaria, de la documentación con que contamos, se han asumido como evidentes dos hechos. El primero, la general cristianización de Hispania a comienzos del siglo v que supone a su vez la rápida desaparición de los templos paganos, pese a que una de las fuentes principales, Orosio, todavía dedica su obra a los recalcitrantes supuestos cristianos que, aprovechando el caos de esos momentos, habían vuelto a su fe pagana, y también a las abundantes alusiones en los textos conciliares a

\footnotetext{
${ }^{1}$ Sanz Serrano (1986: 225-265; 2006: 125-150) sobre la usurpación y las consecuencias políticas para Hispania. He dado especial énfasis a la autonomía de la nobleza local y de las comunidades en sus territorios.
} 
los paganos. El segundo supuesto, el auge de la actividad edilicia cristiana y la evidencia de que la destrucción de un lugar de culto, fundamentalmente pagano, tiene que ver con las llamadas "invasiones bárbaras", lo que paralelamente lleva a soterrar la posibilidad en el caso de las destrucciones de otras causas y por otras manos, por ejemplo las cristianas. En esta línea se ha dado un mayor sentido al testimonio de autores cristianos como Sinesio de Cirene (Oratio, II, 3, 302) y su condena de las acciones destructoras de los bárbaros provenientes del desierto en el norte de África, la profanación de las tumbas, de las iglesias, la utilización de las mesas sagradas y de los utensilios litúrgicos cristianos, que a las abundantes denuncias en la amplia obra de autores como Libanio de Antioquia, el emperador Juliano o el historiador Zósimo, sobre la destrucción de centros de culto paganos como consecuencia de las actividades marcadamente ideológicas de la iglesia y el estado romano en las distintas provincias.

Por lo que se refiere a las Hispanias, de acuerdo con la realidad documental y, pese a la evidencia de que en una situación de relativo caos como la que se dio a principios del siglo $\mathrm{v}$ en Hispania, algunos edificios y lugares de culto - tanto pagano como cristianos - sufrieron ataques y despojos de distintas procedencias, las transformaciones que tuvieron lugar en los espacios religiosos se explican sobre todo en relación con los cambios ideológicos y políticos que tuvieron lugar entre los siglos v-vir. Estos cambios se iniciaron todavía durante el dominio romano y se desarrollaron plenamente con la monarquía visigoda y en ellos tuvieron un papel muy especial las aristocracias locales que influyeron en las poblaciones de los territorios que controlaban. El proceso, que no fue homogéneo ni sincrónico en el territorio hispano, suele aparecer ante nuestros ojos documentado arqueológicamente en su resultado final, es decir, la evidencia de construcciones cristianas entre los siglos $\mathrm{V}$ al vil en lugares donde anteriormente dominaban centro de culto paganos y en otros donde no hay esta constancia documental. Sin embargo, raramente el registro arqueológico nos explica las causas, los medios que se emplearon, los modos y otros factores determinantes de las transformaciones del paisaje religioso. Por el contrario, las fuentes literarias suelen ser más explicitas, aunque no completas en su narración, lo que nos permite plantear explicaciones más o menos aproximadas dentro de un estudio general sobre las transformaciones en los espacios rurales. Pero siempre que tengamos en cuenta las diferencias contextuales y las distintas problemáticas para definir - en este trabajo y en el complementario de Saúl Martín González - las diferencias existentes entre el sistema de villa romana y el de villula de época tardoantigua donde el complejo fenómeno de la cristianización tiene un importante papel.

He defendido en otras ocasiones ${ }^{2}$ que el inicio de la cristianización de las Hispanias se encuentra a finales del siglo IV en la política de los emperadores

\footnotetext{
${ }^{2}$ Sanz Serrano 2003; 2007: 443-480.
} 
cristianos - recogida en el Código Teodosiano - en contra de la libertad religiosa y a favor de la persecución de otras creencias y del cierre de los templos. Lo que no implica que se hayan producido hechos semejantes en épocas anteriores por distintas causas políticas, ideológicas y sociales ${ }^{3}$. De los inicios de la misma en las provincias de Hispania tenemos constancia en un decreto de los emperadores Honorio y Arcadio en el año 409 (Codex Theodosianus, xvi, 10, 15) - el mismo año al que se atribuye la llegada de suevos, vándalos y alanos - dirigido a Macrobio vicario Hispaniarum et Procliano vicario quinque provinciarum en el que en paralelo con la sanción del cierre de los templos se persigue su despojo en un intento de preservar el patrimonio del estado y evitar los conflictos. Este política estatal se sumaba a la llevada a cabo desde hacía tiempo por la Iglesia hispana con sus fieles, tal como se aprecia en los cánones del temprano concilio de Elvira donde se prohibía a los señores cristianos tener en sus casas ídolos para el culto de sus siervos, a no ser que temieran la violencia de los $\operatorname{mismos}^{4}$, y se trataba de impedir que recibieran las ofrendas habituales a los dioses que descontaban los colonos de la renta debida a sus señores cristianos ${ }^{5}$. Pero sobre todo en el mismo se puede apreciar la violencia que generaba la represión de los cultos al anunciar la muerte, se supone a mano de los paganos, de algunos cristianos considerados como mártires en el intento de destruir los ídolos ${ }^{6}$.

Sin embargo, el vacío documental del siglo v - que coincide con la pérdida del control imperial en las provincias y la llegada de los bárbaros - ha determinado que dependamos mas de lo deseable en este periodo tan determinante de la obra del obispo hispano Hidacio quien, en un acto para mí evidente y consciente de damnatio memoriae, elude transmitir cualquier tipo de noticias respecto a la fuerte lucha ideológica desencadenada en los territorios hispanos - y de la que tenemos constancia para otras provincias - y limita sus referencias exclusivamente a los cristianos y sus centros de culto en las regiones de conflicto entre hispanorromanos y bárbaros. Mucho más acorde con los tiempos, aunque escueto y solo válido para las primeras décadas del siglo, es el lamento de su contemporáneo y también cristiano hispano Orosio quien desde el norte de África como "desplazado político" escribió su historia "contra los paganos", es decir, para denunciar la supuesta

${ }^{3}$ Alvar Ezquerra (2014: 261-294) piensa que algunos centros de cultos mistéricos fueron destruídos en el siglo in por diversas causas.

${ }^{4}$ C. 41: Admoneri placuit fideles, ut in quantum possunt probibeant ne idola in domibus suis habeant. Si vero vim metuunt servorum vel se ipsos puros conservent; si non fecerint, alieni ab acclesia habeantur. (Vives 1963: 9).

${ }^{5}$ C. 40: Probibere placuit, ut quum rationes suas accipiunt possessores, quidquid ad idolum datum fuerit accepto non ferant. Si post interdictum fecerint, per quinquennii spatia temporum a comunione esse arcendos. (Vives 1963: 8).

${ }^{6}$ C. 60: Si quis idola fregerit et ibidem fuerit occisus, quatenus in evangelio scribtum non est neque invenietur sub apostolis umquam factum, placuit in numerum eum non recipi martyrum. (Vives 1963: 12). 
"vuelta" al paganismo de unas poblaciones sometidas a las presiones institucionales y convertidas al cristianismo con demasiada urgencia y poca convicción religiosa. Por ello en el prólogo de su obra no duda en dirigirse a su protector Agustín de Hipona para señalarle que escribe contra los paganos que habitaban los pueblos y villas del campo y contra los gentiles a quienes les gustaban las cosas terrenas que no se preocupaban del futuro, olvidaban el pasado y atacaban su tiempo debido a que se adoraba a Dios mientras que los ídolos eran menos adorados ${ }^{7}$.

Se detecta la misma preocupación que trasluce la obra de Orosio por la pervivencia del paganismo en sus más variadas formas en los concilios convocados entre los siglos IV al vir por unos obispos y unos monarcas suevos y visigodos que consideraban cristianos a los habitantes de las provincias, ya que el cristianismo era la religión impuesta por el estado romano, la defendida por la Iglesia y la asumida después por las monarquías imperantes. Así se comprueba primero en el I conc. de Zaragoza del año 380, en un contexto de persecución de los priscilianistas a quienes se consideraba herejes y paganos, en cuyo canon 4 se denunciaban actos durante el solsticio de invierno, entre el 17 de diciembre y el 6 de enero, días del año considerados también sagrados por los paganos, realizados de una manera oculta en las casas o haciendas (in domibus/ in villam) o en los montes ${ }^{8}$. $\mathrm{E} 1$ mismo concilio en el canon 2 especifica las reuniones poco convenientes en domingo y días de cuaresma en los mismos lugares ${ }^{9}$. En estos cánones se puede comprobar la misma coherencia ideológica que mas de un siglo después, y en referencia a los habitantes del alejado norte peninsular, comprobamos en la obra del obispo panonio Martín de Dumio (De correctione rusticorum, 16 ), quien se queja de la "vuelta al paganismo", el abandono del signo de la cruz y el retorno a los ritos y creencias de los antepasados. El obispo, en clara connivencia con el emperador de Oriente y la monarquía sueva, convocó en poco tiempo dos concilios muy importantes en Bracara Augusta, la capital del reino suevo, en los que se estipularon los castigos que debían recibir quienes, en el campo o en las ciudades, se mantuviesen en el error y el pacto con el diablo (cs. 46, 47, 71 y 72 del II Concilio de Braga). Más en concreto, el canon 71 del II concilio de Braga, especifica claramente que se trataba de actividades que seguían las costumbres de

\footnotetext{
${ }^{7}$ Orosius, Historiarum adversum paganos libri septem prologo 9-10 (en la edición de Sánchez Salor 1982).

${ }^{8}$ C. 4: Vigenti et uno die queo a XVImo kalendas ianuarias usque in diem Epifaniae qui est VIII idus kalendas ianuarias continuis diebus nulli licet de ecclesia absentare, nec latere in domibus, nec sedere in villam, nec montes petere, nec nudis pedibus incedere, sed concurrere ad ecclesiam. Quod qui non observaverit de susceptis, anathema sit in perpetuum. (Vives 1963: 17)

${ }^{9}$ C. 2: Ne quis ieiunet die dominica causa temporis aut persuasionis aut superstitionis aut quadragesimarum die ab ecclesiis non desint, nec habitent latibula cubiculorum ac montium qui in his suspicionibus perseverant, sed exemplum et praeceptum custodiant et ad alienas villas agendorum conventum a causa non conveniant. (Vives 1963:16).
} 
los paganos (paganorum consuetudinem). En un contexto semejante, pero en este caso en territorios mucho más amplios dominados por la monarquía visigoda en los siglos VI y VII, los obispos reunidos con sus monarcas en los concilios de Toledo denunciaban todavía la persistencia de las creencias paganas, el culto a los ídolos, las piedras, las fuentes, los árboles y la existencia de personajes especializados en los antiguos ritos, al mismo tiempo que avalaban la política -heredada del imperio romano- de exterminio de los paganos, vigilada en las ciudades por los jueces y los obispos y en el campo por los domini dueños de los grandes predios (como ejemplo, el c. 2 del XVI Conc. de Toledo a. 693 de Egica). La crudeza del enfrentamiento religioso se comprueba sobre todo en el c. 16 del III Concilio de Toledo del año 589, donde se estableció lo siguiente:

Por estar muy arraigado en casi toda España y la Galia el sacrilegio de la idolatría, con el consentimiento del gloriosísimo rey (Recaredo), ordenó el santo concilio lo siguiente: Que cada obispo en su diócesis, en unión del juez del distrito, investiguen minuciosamente acerca del dicho sacrilegio, y no retrase el exterminar los que encuentre, y a aquellos que frecuentan tal error, salva siempre la vida, castíguenlos con las penas que pudieren, y si descuidaren obrar asi, sepan ambos (obispos y juez) que incurrirán en la pena de excomunión, y si algunos señores descuidaren en desarraigar este pecado en sus posesiones, y no quisieren prohibirselo a sus siervos, sean privados también ellos, por el obispo, de la comunión ${ }^{10}$.

Las acciones violentas llegaban también a los espacios funerarios, cementerios o mausoleos, algunos de los cuales podían funcionar como centros de peregrinación y de culto para personajes singulares. De hecho las leyes romanas siempre castigaron con penas muy duras a los violadores de sepulcros, pero también las leyes visigodas (L.V., XI, 2, 1-2) se hacían eco de la existencia de estos delitos dirigidos a robar los vestidos y ornamentos de las tumbas por hombres libres $\mathrm{y}$ siervos. Todavía más, el IV de Toledo del año 633 convocado por Sisenando implicaba en estas acciones a los clérigos en un acto que el concilio consideraba, no obstante, sacrílego y punible ${ }^{11}$.

${ }^{10}$ Quoniam pene per omnem Spaniam sive Galliam idolatriae sacrilegium inolevit, hoc quum consensu gloriosissimi principis sancta synodus ordinavit, ut omnis sacerdos in loco suo una cum iudice territorii sacrilegium memoratum studiose perquirat, et exterminari inventa non differat; omnes vero, qui ad talem errorem concurrunt, salvo discrimine animae, qua potuerit animadversione coerceant. Quod si neglexerint, sciant se utrique excomunicationis periculum esse subituros. Si qui vero domini extirpare hoc malum a possessione sua neglexerint vel familiae suae prohibere noluerint, ab episcopo et ipsi a comunione pellantur. (Vives 1963: 499).

${ }^{11}$ C. 46: Si quis clericus in demoliendis sepulchris fuerit deprehensus, quia facinus hoc pro sacrilegio legibus publicis sanguine vindicatur, oportet canonibus in tali scelere proditum a clericatus ordine submoveri et poenitentiae trienium deputari. (Vives 1963: 499). 
Desconocemos el alcance de las disposiciones eclesiásticas a favor de la persecución de los paganos y la destrucción de sus centros de culto, aunque es evidente en esta época la existencia de iglesias cristianas al menos en las ciudades y en algunas zonas rurales controladas por la Iglesia. Sin embargo, todavía en el año 681 el monarca Ervigio reunido con los obispos en el XII Concilio de Toledo esgrimía las mismas amenazas contra quienes desobedecían las leyes y ante la desolación que suponía el precario avance en la cristianización en una buena parte de las provincias hispanas. Pero lo sorprendente no es solo su lamento sobre el fuerte arraigo de las costumbres paganas entre el pueblo, sino que en el canon 11 se considera responsable a la nobleza (no sabemos en qué porcentaje) por no perseguir lo suficiente a sus dependientes y por incurrir ella misma en los errores de la fe. De manera que los reunidos en el concilio encomendaban a los jueces castigar con azotes y cargar con cadenas a los prevaricadores y exigían bajo juramento a sus dueños (se suponen por lo tanto que eran esclavos y siervos) la vigilancia de estos crímenes, bajo la amenaza de perder sus derechos sobre ellos y caer bajo la pena de la excomunión perpetua; además se amenazaba a los señores con el destierro y las consiguentes pérdida de sus bienes y el rechazo social que la excomunión suponía ${ }^{12}$. Finalmente el c. 2 del XVI concilio de Toledo en época de Égica (693), además de amenazar incluso a los presbíteros, jueces y nobles que no cumplieran con su obligación respecto a la persecución de los paganos, sancionaba definitivamente un hecho que se venía dando en todo el espacio peninsular y que explica en gran parte la transformación lenta, pero segura, de los espacios religiosos rurales, me refiero a la obligación de ofrecer a las iglesias cristianas vecinas los dones que las gentes depositaban en los espacios dedicados a los cultos tradicionales paganos de más o menos reciente construcción.

Lo que se evidencia en estos concilios es el papel determinante de la nobleza local en el mayor o menor éxito de la acción de los obispos y jueces. Sobre todo porque, como afirmaba en el siglo $\mathrm{V}$ el obispo Salviano de Marsella en su De gubernatione Dei, una buena parte de las poblaciones de las provincias de la Galia y de Hispania y aún sabiendo que ellos suponía la pérdida de sus propiedades, se habían arrojado en manos de la nobleza buscando protección -mediante los sistemas del patrocinio vicorum (de vici-aldeas) y el vicanorum (de vícanos, aldeanos)- frente a la inseguridad de los tiempos por la presencia de los bárbaros en las provincias y como defensa ante las tremendas presiones fiscales de la época. Esta

${ }^{12}$ C. 11: Eos vero qui ad talem horrorem incurrunt et verberibus coerceant et onustos ferro suis dominis tradant, si tamen domini eorum per iusiurandi adtestationem promittant se eos tam sollicite custodire, ut ultra illis non liceat tale nefas conmittere. Quod si domini eorum nolint huiusmodi reos in fide sua suscipere, tunc ab eis a quibus coerciti sunt regiis conspectibus prasententur, ut principalis auctoritas liberam de talibus donandi potestatem obtineat: domini tamen eorum qui nuntiatos sibi talium servorum errores ulcisci distulerint et excomunicationes sententia perferant et iura servi illius quem coercere nolint se amisisse cognoscat quod si ingenuorum personae his erroribus fuerint inplicatae et perpetuae excommunicationis sententia ferientur et aretiori exilio ulciscentur. (Vives 1963: 399). 
realidad no solo forma parte, como se ha querido defender en ocasiones, de los excesos retóricos del obispo marsellés, pues los concilios y otras fuentes de la época demuestran sobradamente el enorme poder económico, político y ideológico de la nobleza hispana en los territorios que poseían ${ }^{13}$. Al respecto es importante señalar, y aunque un análisis detallado de los pormenores no puede ser tratado en este estudio, el hecho de que materialmente el poder ejercido por la nobleza hispana en el campo y en la ciudad aparece simbolizado en la magnitud y riqueza de las grandes villas que poseían y en las que tenían bajo su control a un buen número de siervos y dependientes ${ }^{14}$.

Pero además interesa resaltar que en los grandes dominios que incluían estas villas, también en ambientes rurales, se situaban los templos de los dioses a los que acudían a orar, buscar consuelo o curación y a entregar sus ofrendas las poblaciones de los alrededores o de puntos muchos mas alejados en el caso de los templos con mayor prestigio. $\mathrm{Y}$ es precisamente a estos centros de culto y a quienes acudían allí, incluso bajo la amenaza de la persecución, a quienes se refieren mayoritariamente lo cánones conciliares analizados. Bien se trate de centros adscritos a una villa - y controlados por su dueño laico - o de lo que considero villas-templo o "dominios de los dioses" donde siervos, dependientes y sacerdotes que pertenecían a distintas divinidades, tarde o temprano sufrieron el peso de las leyes y de las disposiciones eclesiásticas, un fenómeno este necesitado de una profunda investigación. Aunque el investigador, a la hora de analizar los hechos y especular con los tiempos, formas y significados, ha de ser muy cuidadoso con los documentos materiales que le llegan, ya que éstos no siempre provienen de excavaciones sistemáticas, o no definen estructuras claras o pueden confundirno con iconografías y estilos artísticos o usos de larga pervivencia como sucede con las plantas basilicales o los mosaicos ${ }^{15}$.

Pero es incuestionable que una buena parte de la destrucción de edificios y centros paganos está relacionada con el desarrollo del fenómeno cristianizador de las Hispanias. Ya que del mismo modo que la retórica y la acción misionera tenía como objetivo cambiar las mentes y las creencias de los habitantes de las provincias, la destrucción de los edificios y de los paisajes que llamamos paganos tenía

${ }^{13}$ He trabajado toda esta problemática en Sanz Serrano 2007: 443.

${ }^{14}$ Hay abundantes trabajos que mantienen la pervivencia de las grandes villas mucho después de la llegada de los bárbaros y el mantenimiento de su producción agrícola y artesanal eficiente (Orfila 1993: 125-147; Orselli 1999: 181-193; Gelichi 2000: 115-139).

${ }^{15}$ Un ejemplo sería la interpretación de los ricos mosaicos de época tardía en villas supuestamente cristianas y que conservan temas paganos como La Cocosa en Extremadura, la de Vitale en Tossa de Mar (Gerona), la de Cardilius y Avita de la villa de La Malena en Zaragoza, la de Quintana del Marco en León, las palentinas de Dueñas y La Olmeda, en Pedrosa de la Vega, Almenara de Adaja en Burgos, villa Fortunatus en Fraga (Huesca) y un largo etcétera. Es difícil suponer que la Iglesia en sus predios o la nobleza cristiana mantuvieran durante mucho tiempo estos testimonios porque los consideraban meros motivos artísticos como se ha argumentado (Arce 1993: 265- 274). 
como objetivo la creación de un nuevo espacio cristiano, al servicio de una nueva ideología, para el que se aprovecharon siempre que hubo ocasión los materiales y riquezas requisadas. $\mathrm{Y}$ es fundamentalmente en relación con este proceso como podemos y debemos explicar la desaparición de la villa clásica como estructura señorial y su transformación en nuevos tipos de organización social, política y económica, como fueron la parrocbia u organización territorial cristiana local y la villula como nueva forma de ocupación del suelo en la que se aprecian importantes cambios respecto a los antiguos predios señoriales.

Sobre lo temprano de este proceso, a mediados del siglo IV tenemos el testimonio muy conocido de la conversión de Prisciliano y de otros nobles del norte peninsular, un hecho histórico que ha sido tratado por buenos especialistas ${ }^{16}$. Los mismos priscilianistas admitían provenir de un pasado pagano muy comprometido (Prisciliano, Libro Apologético, 15) que considero pudo significar el compromiso sacerdotal de algunos de sus líderes, como Prisciliano, con algún culto concreto. Así al menos sucedía con una buena parte de las intelectuales en las provincias galas, y en especial con los que estudiaban en Burdeos donde impartían la paideia clásica todavía en el siglo iv los más famosos rétores paganos de Occidente. Entre ellos cabe destacar el llamado Acio Patera por el poeta Ausonio en su Commemoratio (4) que era "vástago de una familia de druidas de Bayocaso" (Bayeux, Calvados), del sagrado linaje del templo de Beleno e iniciado en los misterios de Apolo. En relación con esta realidad no se ha tenido en cuenta que a esta escuela pertenecía el rétor Delfidio que era precisamente el padre de la compañera sentimental de Prisciliano, ejecutada junto con su madre y el líder tras ser condenados en un concilio en esa ciudad por heréticos y paganos (Ausonio, Comm. 5), lo que demuestra la relación del líder priscilianista con estos círculos culturales y sobre todo sacerdotales bordeleses ${ }^{17}$. Por lo tanto, aún cuando fueron los priscilianistas acusados de practicar ritos prohibidos en los montes y en la intimidad de las villas, es de suponer que su conversión tuvo que tener unas consecuencias para los templos situados en sus dominios, siendo éste un supuesto sobre el que no tenemos ninguna documentación. En el caso de que esas transformaciones en centros cristianos no llegasen de la mano de los priscilianistas, pudieron ser llevadas a cabo por el obispado hispano que los persiguió, desterró y requisó sus bienes para apropiárselos. Pero sobre el particular tampoco hay evidencias en los textos ni en la documentación arqueológica relativa a los comienzos del siglo $\mathrm{V}$ y, por otra parte, la condena de los priscilianistas no tiene porqué suponer una inmediata cristianización de los espacios paganos en los que se movían, ya que la iglesia más conservadora del sur peninsular carecía de los medios y del material humano necesario para conseguir una transformación visible rápida en las pose-

\footnotetext{
${ }^{16}$ Blázquez Martínez 1981: 210-236; Vilella Masana 1997: 177-185; Escribano Paño 1988.

${ }^{17} \mathrm{Al}$ respecto Sanz Serrano 2000; 2007.
} 
siones requisadas. Menos aún cuando apenas dos décadas después las Hispanias fueron "invadidas" por los bárbaros.

Los priscilianitas no son los únicos ejemplos que nos llegan de la conversión de las élites provinciales; el cambio religioso lo veíamos reflejado en los cánones del Concilio de Elvira y en la ley del 409 dirigida a nuestras provincias y se intuye en una epístola del papa Hilario fechada a mediados del siglo v que parece demostrar la cristianización de unos personajes del Valle del Ebro denominados como optimi et plurimi provinciales, honorati et possesores de los territorios de las ciudades de Turiasso, Cascantum, Calagurris, Vareia, Tritium, Lejía (Libia) y Virovesa. Aunque en realidad la epístola solo refleja la participación de estos hombres destacados en la controversia desatada por el control de los obispados del Valle del Ebro, sin que por ello debamos inferir su segura cristianización ${ }^{18}$. Tampoco del dato un tanto ambiguo de que la joven aristócrata cristiana Melania y su esposo Piniano habían intentado vender algunas de sus posesiones peninsulares y otras convertirlas en monasterios, primero porque fracasaron en el intento por la presencia de los bárbaros en ellas y, por otra parte, porque no sabemos el alcance real que esta política hubiera tenido de haberse podido llevar a efecto. ${ }^{19}$ De hecho, hay claras evidencias de que, al menos en el territorio burgalés y cántabro los santuarios tuvieron una larga pervivencia ${ }^{20}$. Por ampliar los ejemplos, desconocemos la repercusión real en las transformaciones del paisaje religioso y el impacto que ello puedo tener en las poblaciones de la conversión forzada y la imposición del culto a San Félix que llevo a cabo Paulino de Nola hacia el año 395 en los predios de su esposa la hispana Terasia en algún lugar de la Tarraconense, un hecho al que se alude constantemente para suponer la rápida cristianización peninsular ${ }^{21}$.

En mi opinión el inicio del proceso de cristianización y su problemática está mejor documentado en las fuentes visigodas. $Y$ en particular en el episodio real o simbólico, pero altamente sugerente, ambientado en el siglo vi y recogido por las Vitas Sanctorum Patrum Emeretensium (VPE 3,44) 22 en las que se narra el temor de los habitantes de ciertos dominios, al parecer requisados ya que se les reconoce del fisco, cuando Leovigildo se los entregó al monje africano Nacto y

${ }^{18}$ Controversia desatada por la queja del metropolitano de Tarraco ante las ordenaciones de obispos que estaba llevando a cabo sin su consentimiento el obispo Silvano de Calahorra. Lo que parece ser una disputa entre obispos, incluye a personajes laicos. Al respecto, Ep. $14 \mathrm{de}$ Ascanius (Vilella Masana 1990: 385-39).

${ }^{19}$ Blázquez Martínez 1974: 103-123.

${ }^{20}$ Así lo hemos defendido respecto al de Vurovius en la zona burebana en Sanz Serrano; Ruiz Vélez 2014: 311-338.

${ }^{21}$ Terasia era una mujer muy piadosa pero Paulino fue sospechoso de haber participado en la muerte de su hermano y por eso se enclaustró. Véase Gruber 2006: 359-382; Álvarez Solano; Hurtado Buscató; Rivas García 1999: 275-300.

22 (Ed.) Camacho Macías 1988. 
a sus compañeros para que fundaran monasterios. Como consecuencia, se produjo el asesinato del monje a manos de los campesinos (homines habitantes in eodem loco), a quienes el personaje les era extraño por su origen, por su cultura y mentalidad y por llevar una vestimenta de pobre que le impedía ser respetado; aunque particularmente considero que tal violencia encerraba las represalias de esas comunidades ante la acción destructora de los edificios de culto pagano por parte de los recién llegados. Pero a pesar de este texto tan elocuente, que debemos sumar a los cánones conciliares visigodos vistos anteriormente que demuestran la persecución y la destrucción de los lugares y símbolos paganos, también es difícil elaborar un modelo de las características y cronologías de las transformaciones del espacio religioso en la etapa de pleno dominio de la monarquía visigoda. La razón fundamental es que las fuentes narrativas, como por ejemplo Isidoro de Sevilla o Juan de Biclaro, prefieren concentrar sus denuncias en las herejías y las desviaciones dogmáticas y dar por sentado que en un sistema de monarquía cristiana los súbditos no podían ser otra cosa que cristianos.

No obstante contamos con un pequeño número de obras de carácter hagiográfico en las que se puede comprobar en unos casos la reticencia de muchos territorios a la conversión y, en otros, la tardía llegada de cristianos a determinados lugares para llevar a cabo su labor misionera. También cómo esta estuvo protagonizada generalmente por miembros de las élites territoriales en sus propios dominios. Así al menos parecen ser los casos de Fructuoso, personaje hijo del dux exercitus Spaniae que llevó acabo una labor de evangelización en el norte y fundó monasterios en los obispados de Braga y Dumio, muy decaídos en la fe impuesta por Martín décadas antes; de Valerio, en el Vergidense territorium que pertenecía a su familia y donde tuvo problemas con el obispo de Astorga por el control ideológico de las poblaciones y de los donativos que llegaban al monasterio enviados por los fieles (Valerio, Replicatio 7-9); de Emiliano cuya vida narrada por Braulio de Zaragoza relata su labor en el Alto Valle del Ebro en territorios que pertenecían a su familia, y de Vicente de Huesca que tenía 26 propiedades en la Tarraconense y una de ellas la convirtió en el monasterio de Asan donde incluyó a sus colonos y siervos ${ }^{23}$. A ellos podemos sumar los numerosos ejemplos presentados por Ildefonso de Toledo en su De viris illustribus ${ }^{24}$, obispos a los que podemos considerar como grandes transformadores de los territorios, castra, vici, pagi y villae que les pertenecían por herencia familiar. Por lo tanto es evidente la acción de las elites cristianas, poseedoras de grandes predios y lujosas villas, en el fenómeno de la transformación del espacio rural y de su cristianización, mediante la fundación de iglesias y de monasterios y la imposición de la nueva fe por las

${ }^{23}$ Castellanos 1998; 2004. Se ha especulado que la organización eclesiástica posterior se correpondiese con centros anteriores de poder al menos en el noroeste (véase Díaz 2001: 329-359).

${ }^{24}$ Codoñer Merino: 1972. 
buenas o por la fuerza a sus siervos y esclavos que en los concilios aparecen denominados como familia ecclessiae ${ }^{25}$.

De acuerdo con ello, ¿Cabe entonces pensar que los amplios espacios de la villa clásica fueron compartimentados para conformar espacios menores o villulae presididas por construcciones cristianas?. Por desgracia carecemos para Hispania de un discurso contemporáneo donde se puedan apreciar estos hechos y los cambios religiosos, sociales y económicos que supusieron. Sin embargo, hay ciertos textos de procedencia oriental donde se aprecian en gran amplitud y de manera descarnada porque provienen de buenos narradores. Entre ellos el emperador Juliano, ferviente denunciante de los abusos y consecuencias de las destrucciones de edificios paganos y de la persecución religiosa en Oriente en sus discursos y epístolas y, sobre todo, el rétor pagano Libanio de Antioquía que en su Pro Templis (Oratio XXX, 8-10) explica el proceso de cambio que se estaba llevando a cabo desde finales del siglo iv. Debemos detenernos en este último por su testimonio ejemplificador y sobre todo porque afirma y demuestra como se producían los hechos, sin contemplaciones hacia la masa de esclavos, colonos y trabajadores de las más variadas categorías que cultivaban y trabajaban en los templos de los dioses y que al mismo tiempo dependían de su existencia. Libanio refiere al emperador Teodosio las destrucciones y saqueos de estos lugares sagrados a manos de los monjes que hacían huir a sus sacerdotes y desencadenaban el abandono de sus tierras por los campesinos (y debemos suponer el freno de sus actividades industriales) sin ofrecer otra alternativa, de manera que las consecuencias eran la ruina de los campos y de los hombres cuya alma eran los templos, que habían edificado y mantenido, y en los que tenian puestas sus esperanzas con sus familias y sus animales y su tierra sembrada; esperanza perdida después de su destrucción y de la privación de sus dioses. El autor mantiene igualmente en otro de sus discursos (Oratio II, 30-32) la desconfianza de los fieles que con el cambio religioso exigido por el estado a favor del cristianismo habían dejado incluso de entregar ofrendas a los templos que todavía estaban en funcionamiento para que éstas no acabasen finalmente en manos de otros (se supone los cristianos) y habían dejado de practicar los sacrificios y los ritos que daban riquezas a los templos y servían para auxiliar a los necesitados, desencadenando con ello la pobreza para todos. Por lo tanto, para el autor, el drama de la persecución religiosa también lo era social y afectaba al sistema económico que además dejaba sin ayudas a los ancianos y a los niños huérfanos con los cuerpos lisiados que no recibían la atención médica que necesitaban, ayuda que el mismo Libanio conocía bien porque sus constantes dolores de cabeza solo encontraban alivio en las medicinas que recibía en el templo de Esculapio. A todo ello se venía a añadir según el emperador Juliano (ep. 84) el freno de las ayudas imperiales que iban destinadas a los templos para que los sacerdotes compraran alimentos y construyeran hospicios para los po-

\footnotetext{
${ }^{25}$ Cs. 6 del 11 de Toledo y 4 del III de Zaragoza (Vives 1963: 360; 478).
} 
bres, para sus servidores y los extranjeros y mendigos que participaban también de las ofrendas de los fieles; aunque este emperador extiende sus críticas a cierto sacerdocio pagano más dedicado al lujo y los placeres y causante de que judíos y cristianos supliesen con sus obras caritativas las prácticas tradicionales de los paganos ${ }^{26}$.

Consecuentemente, la persecución religiosa y la desaparición de sus símbolos y manifestaciones supuso un cambio en el paisaje y en la organización del espacio religioso con una grave pérdida para la comunidad pues, por ejemplo, en la descripción que Libanio hace del templo de Apolo en Dafne (cerca de Antioquía) (Oratio, XI, 235-245) afirma que contaba con un teatro, bosques de cipreses de fragancias embriagadores y con multitud de pájaros, viñedos, senderos, residencias majestuosas, salas para fiestas, jardines, baños restauradores de la salud y una gran riqueza acuífera que era utilizada para las curaciones de los enfermos que allí acudían. Por contraste, el autor en otro lugar (Oratio VII, 9-11) llega a afirmar que, una vez dañados, la mayor parte de las veces los antiguos lugares de culto se convertían en basureros, en depósitos de escorias o de leña o acababan por ser demolidos y sus piedras utilizadas para la construcción de casas. Como consecuencia, el historiador Zósimo (V,23) asegura también que al desaparecer los templos muchas de sus antiguas actividades pasaban a ser realizadas en las mansiones y villas de personajes distinguidos, tal como veíamos en los cánones de los concilios de Zaragoza y el I de Toledo ya analizados referidos a las actividades supuestamente heréticas y paganas de los priscilianistas. Pero la transformación del paisaje religioso tuvo diversos tiempos según los contextos y dependió sobre todo de la capacidad de la Iglesia para crear y desarrollar las infraestructuras necesarias para su control y la organización de una nueva forma económica y social que, en parte, emanaba del pasado pero adquiría un nuevo significado. Aún así Libanio (Oratio, XXX, 26-28) era consciente de que la imposición del cristianismo no significaba necesariamente su aceptación.

Como es lógico las transformaciones producidas más o menos rápidas, coinciden con un cambio terminológico en los textos mediante la paulatina desaparición, aunque no radical, del término villa y la irrupción, no novedosa pero sí significativa, del término villula con un significado muy distinto al de parrochia. Aunque se ha especulado ${ }^{27}$ con la posibilidad de que la villula podría ser una villa más modesta porque así parecen demostrarlo las referencias de épocas anteriores, es indudable que en época visigoda en el concepto se incluye una diferencia de función, de organización e ideológica además de la cuestión relativa al tamaño. Así debemos de tener en cuenta que en los primeros concilios de los siglos iv y v, cuando era escasa la cristianización de las provincias, los cánones que se refieren a los paganos, retirados para organizar sus ritos fuera del control eclesiástico en sus

\footnotetext{
${ }^{26}$ Enjuto Sánchez 2000: 407-423 ha estudiado algunos casos de estas evidencias en Oriente.

${ }^{27}$ Martín González 2011.
} 
posesiones y casas donde había altares y templos, no utilizan el término villula. E1 Concilio de Elvira en su canon 41 utiliza in domibus, y el I Concilio de Zaragoza del año 380, en el c. 4 se refiere a la villa o a los montes como competencia de las iglesias (nec sedere in villam, nec montes petere, nec nudis pedibus incedere, sed concurrere ad ecclesiam). El canon 2 de este último insiste en habitáculos, montes y villas ajenas (nec habitent latibula cubiculorum ac montium et ad alienas villas). Sin embargo, en el inicio del esplendor de la monarquía visigoda, casi dos siglos después y puesto ya en marcha el aparato del estado para la cristianización de los territorios, el c. 16 del III Concilio de Toledo en el año 589, se refiere de una manera ambigua a actos idolátricos permitidos por los señores en sus posesiones (a possessione sua), ambigüedad que no nos permite aclarar qué tipo de lugares son, pero es significativo que se haga referencia a la familiae del dominus, los siervos y dependientes que habitualmente trabajaban para una villa, pero también para un sistema señorial ya transformado. Por el contrario, en un texto de clara significación cristiana, la ya referida obra sobre los padres emeritenses (VPE, II, 21), en el pasaje donde se cuenta al desbordamiento del río Guadiana, se comenta la inundación de edificaciones situadas en las villulae vecinas situadas en los bordes de río, lo que parece demostrar un tamaño modesto de las mismas, aunque lo más sugerente es la relación de éstas con el monasterio Caulaniense que actuaba como punto de referencia ideológica para las mismas ${ }^{28}$. Es decir, ha habido una cristianización del territorio y posiblemente una compartimentacion del mismo de posesiones anteriormente más amplias que pudieron pertenecer tanto a grandes señores paganos como a los emperadores ya desaparecidos o ser nuevas organizaciones socioeconómicas creadas con la transformación religiosa en la zona. Algo semejante tenemos en la obra de Julian de Toledo (Historia Wambae, 3: Gerebantur enim ista in villula, cui antiquitas Gerticos nomen dedit) donde el término villula va ligado a un centro de población, el de Gerticos, en territorio Salmanticense, supuestamente ya cristiano y originado en una organización anterior del tipo villa clásica. Todavía más, hay testimonio de la construcción de un cenobio femenino en una villula en la obra Beati Ildephonsi Elogium de Julián de Toledo ("Coenobium quoque virginum in Deibensi villula construxit en PL, XCVI, 43) y en la Vita Iuliani (VI, XCVI, 446: Monasterio Sancti Felicis, quod est Cabensi in villula dedicatum) de Félix de Toledo, donde se dice que se dedicó un monasterio a San Félix en una villula".

Los ejemplos se multiplican si atendemos a los concilios que nos permiten ver algunas diferencias nuevas. Así el Concilio XII de Toledo, en el intento de frenar los nombramientos de obispos sin el control del Metropolitano de Mérida,

28 (VPE, II, 21): Post quidecim vero aut eo amplius annos memorabilis amnis Ana nimium excrecens ripasque alvei sui supergrediens fluenta liquoris lat asparsi et ruinas aedium per villulas vicinas litori suo multas fecit, similiter et Caulaniensis monasterii cellas evertit. 
corrobora en el canon 4 la existencia de villulas, la construcción de monasterios en ellas y la ordenación de un nuevo obispo en la de Aquis - por presiones del rey Wamba - donde descansaba el cuerpo del confesor Pimenio ${ }^{29}$. Un poco más adelante se asegura que se estaba haciendo lo mismo en otros lugares y villulas, negándole a Aquis el privilegio de tener obispo. Si pudiéramos identificar la Aquis del concilio con la Aquae Flaviae (Chaves) que fue la sede obispal de Hidacio, lo que estamos viendo es la pérdida de la importancia eclesiástica del lugar en dos siglos y, muy probablemente, la transformación de un antiguo dominio familiar que encumbró a Hidacio como obispo, en compartimentos menores dependiente de la Iglesia hispana. Este mismo concilio, en el tomus previo, se refiere a la famosa ley militar de Wamba por la que se obligaba a los nobles a acudir a la llamada del rey en época de guerra y pone de manifiesto que algunos habitantes de las provincias habían sido declarados infames al no responder al requerimiento; pero lo que importante es que al señalar sus lugares de pertenencia utiliza los términos vici y villula $e^{30}$. Por lo tanto en ninguno de los casos citados vuelve a aparecer el término villa para caracterizar formas de organización territorial al estilo de la villa clásica y sí el de villula siempre relacionado con la cristianización del lugar.

Este cambio terminológico evidente se aprecia plenamente relacionado con un cambio estructural en otros textos tardios. La Regula Communis (VI) clarifica más sus características, ya que corrobora que en las villulae se podían encontrar espacios religiosos relacionados con el cristianismo e incluso monasterios familiares donde se incluían las mujeres y los hijos de los siervos y se construían hospicios para peregrinos bajo el modelo de los antiguos templos paganos como hemos visto más arriba. Además especifica cómo sus habitantes debían renunciar a la posesión de sus bienes y villulae que ya abandonaron. Por lo tanto, éstas son un patrimonio perdido de mayor o menor envergadura al que se tenía que renunciar en la vida monacal para entregarlo a la Iglesia. Pero lo interesante es que la Regula identifica otros lugares de hábitat donde no existen estos monasterios, los vici y las villae, entidades por lo tanto que en esa época son plenamente identificables como distintas a la villula. ${ }^{31} \mathrm{El}$ caso de la villa es una excepción respecto a la mayoría de los textos cristianos de estos siglos, donde prácticamente está desaparecida como unidad territorial, y lo cierto es que no podemos determinar

${ }^{29}$ C. 4 .....Ut in monasterio villulae Aquis ubi venerabile corpus sanctissimi Pimenii confessoris debito quiescit honore, novam episcopalis honoris ordinationem efficeret. (Vives 1963: 390-392).

${ }^{30} \mathrm{C} .2$... Ita ut quia in quibusdam villulis vel territorios sive vicis... (Vives 1963: 383).

${ }^{31}$ Regula Communis VI (PL LXXXVII): Cum venerit quispiam uxore vel filiis parvulis id est infra septem annos, placuit sanctae communi regulae ut tam parentes quam filii in potestatem se tradant abbatis, qui et ipse abbas omni sollicitudine quid observare debeant rationabiliter eis disponat: primum nullam corporis sui potestatem habeant, neque de cibo aut indumento recogitent. Neque facultates aut villulas quas semel reliquerunt ulterius possidere praesumant; sed tamquam hospites et peregrini subiecti in monasterio vivant... Reg. Comm., XXII: ... Ceterum vicos, villasque circuire adque ad saecularem possessionem accedere non licebit. 
si ésta era concebida en estos momentos como lo había sido hacía dos siglos y conservaba los valores de su pasado pagano y romano, aunque parece determinar un patrimonio privado en algunos documentos civiles, jurídicos y literarios ${ }^{32}$.

Independientemente de lo que encierre el significado del término villa en el siglo vir, lo que parece incuestionable es que villa y villula no son términos intercambiables sino que coexisten en época visigoda identificados por sus contemporáneos en sus diferencias estructurales y funcionales. Diferencias que no se presentan demasiado claras debido a la precariedad de información en los textos, pero que parecen tener relación con la cristianización de los espacios rurales y muy probablemente con una compartimentación del territorio de los antiguos dominios señoriales para el caso de las villulae. La transformación en ese caso tuvo mucho que ver con las creencias e ideologías de sus respectivos dueños, en el caso de que fueran privadas, o de la iglesia en los espacios que le pertenecían por herencia patrimonial o expropiación a otros dueños. Personalmente creo que las villulas tuvieron mucho que ver con una transformación del paisaje rural como consecuencia de la descomposición de una parte de los antiguos grandes predios de época romana, bien por razones políticas, económicas o ideológicas (la persecución cristiana a la que me he referido más arriba), pero también como reflejo tardío de la existencia histórica de pequeñas y medianas propiedades libres que, con la descomposición del estado romano, pudieron ser más fácilmente controladas por la Iglesia. En ambos casos, el cambio ideológico se detecta en la construcción en ellas o en su entorno de monasterios y de iglesias rurales y la transformación de sus hombres libres en cristianos y de los siervos que habitaban las propiedades heredadas por la iglesia en la familia ecclessiae.

Fueron fundamentalmente estos miembros de la familia ecclessiae los elementos idóneos para el mantenimiento de las nuevas estructuras eclesiásticas creadas en los antiguos espacios sagrados paganos. Pues, si bien es evidente que no se puede hablar de la cristianización de los espacios rurales si solo contamos con pruebas de la destrucción de los templos paganos, ya que, como veíamos en Libanio, éstos podían ser abandonados o utilizados para otros menesteres más laicos como establos o almacenes, si hay abundantes testimonios en que construcciones cristianas sustituyeron a los anteriores edificios paganos en ellos como manifiestan los textos. No es mi intención abundar en este asunto, ya que en esta misma publicación, Saúl Martín González presenta algunos de los casos más destacados de estas transformaciones en su contexto material. Por mi parte, hace tiempo que llevo defendiendo que las antiguas Hispanias tardaron siglos en vaciarse de templos paganos y que este proceso fue más rápido en las ciudades que en el campo, ya que algunos de ellos estuvieron enclavados en parajes alejados e insólitos

${ }^{32}$ Liber Iudiciorum, II, 4, 17 y VIII, 6, 2 y Valerio del Bierzo, De superioribus querimonis residuum, III, 13, 15 . 
o lejos de los centros de población importantes ${ }^{33}$. Y al respecto remito en este momento a los evidentes casos de la cristianización del santuario de Ataecina en Santa María del Trampal o el de Endovélico en San Miguel de la Mota en Alandroal, Portugal, los dos con claros rasgos de destrucción y reutilización de sus materiales en la etapa cristiana. Además el fenómeno puede ser extendido a la construcción de iglesias en las antiguas villas que mantenían centros religiosos al servicio de sus dependientes y siervos. Como sin duda sucedió en las más ricas de la Península como Las Vegas de Pueblanueva, la de de Fortunatus en Fraga, la de São Cucufate en el territorio de Pax Iulia (Beja-Portugal), Francolí en Tarraco, La Cocosa, Las Tamujas en Toledo, Santa Lucía de Aguilafuente en Segovia y Santervás del Burgo en Soria, algunas de ellas con una datación muy tardía como las de Veranes en Gijón, de São Gião cerca de Nazaré, Valdecebadar de Olivenza, S. Juan de Baños en Palencia o S. Pedro de la Nave y Quintanilla de las Viñas. Yo misma he podido comprobar el fenómeno tardío de las transformaciones de los espacios rurales a partir del estudio del santuario de Vurovius en Barcina de los Montes, situado en un importante cruce de caminos entre la Meseta, Cantabria, el Valle del Ebro y la Galia y cuyo paso estaba controlado en los Montes Obarenes por el yacimiento de Soto de Bureba que hemos identificado con la civitas autrigona de indeleia $^{34}$. Esta zona de cristianización tardía acabaría por convertirse finalmente en un enclave importante en el Camino de Santiago.

En definitiva, debemos ser tan cautelosos y precisos a la hora de aplicar las cronologías de los procesos, cuanto en los estudios de los materiales de los distintos contextos, ya que el fenómeno de la cristianización de las antiguas hispanias fue un proceso largo y muy complejo. Porque la construcción de edificios cristianos en lugares donde antes existieron centros de culto pagano o no, requirió contar con un importante componente humano capaz de mantenerlos en pie, cuidarlos, asegurar la labor misional entre los habitantes de la zona y posibilitar su funcionamiento. Por eso en los textos se comprueba cómo la Iglesia se organizó a base de la misma estructura social que anteriormente componía el elemento humano de las villas y de la que se nutrieron los antiguos centros de culto paganos para su mantenimiento y desarrollo. Es decir, de la estructura social campesina que ponía en manos de los grandes predios a un buen número de siervos y de dependientes. En el mundo pagano, los templos rurales funcionaron gracias a las ofrendas que recibían de las poblaciones cercanas, pero también de las rentas que provenían de

${ }^{33}$ Sanz Serrano 2003. El proceso no comenzó a ser importante hasta el siglo vi e incluso podemos llegar en algunas hasta época Omeya (Caballero Zoreda 2000; Godoy Fernández 1998) que presentan el debate abierto sobre las cronologías y las posturas adoptadas por los distintos especialistas respecto a centros como Santa Lucia del Trampal en Cáceres, Santa María de Melque, S. Pedro de la Mata en Toledo, Quintanilla de las Viñas en Burgos o Santa Comba de Bande en Orense entre otros. También Guerra; Schattner; Fabião; Almeida 2002; Schattner; Suárez Otero; Koch 2003.

${ }^{34}$ Sobre la problemática: Sanz Serrano; Ruiz Vélez 2014. 
su trabajo en los campos de los dioses o como artesanos, administradores, cuidadores y sacerdotes de los mismos. Libanio de Antioquía era muy claro cuando incidía, como hemos visto más arriba, en este fenómeno, sintetizándolo en su frase de que los templos eran "el alma de los campos". Con su cristianización las iglesias se sustuvieron igualmente con el trabajo de los miembros de la llamada familia ecclesiae y de esta misma familia salieron los encargados de organizar el culto y mantenerlas en pie donde se construyeron, a veces en parajes recónditos.

De nuevo los cánones conciliares son en Hispania testimonio de estos hechos. El IV Concilio de Toledo en su canon 49 se refiere a la acogida de los siervos como monjes por voluntad propia si eran adultos o por la de sus padres en el caso de los menores, al mismo tiempo que se les negaba la posibilidad de volver al mundo si se arrepentían ${ }^{35}$. El mismo concilio en su canon 5 señala que los tonsurados no podían volver a la vida seglar aunque hubieran sido entregados a la iglesia por sus padres y sin su permiso o lo hicieron ellos mismos al quedar desprotegidos a la muerte de sus padres, condición que se repite para las viudas y vírgenes consagradas en los monasterios. El mismo canon deja claro que si han huído y son apresados por el obispo (en este caso actúa como el dominus en la villa), una vez cumplida la penitencia que se supone tendrían por no cumplir con sus obligaciones, caerían bajo el anatema al ser considerados como apóstatas de la fe. La dedicación de por vida iba aparejada incluso en el caso de que los padres no hubieran dado su consentimiento, hecho que nos pone en relación con la imposición de la Iglesia como patrona a sus siervos y que está reflejada en el canon 6 del $\mathrm{X}$ concilio de Toledo junto con las razones que llevaban a algunos padres a entregar a sus hijos antes de cumplir los 10 años de edad y que no eran otras que el niño pudiera "salir de la miseria", es decir, la esperanza de que bajo la protección del templo su vida mejorase respecto a la que les esperaba en el ámbito familiar. Pero requiere una especial atención el canon 12 del Concilio de Mérida del año 666 en que podemos comprobar la necesidad de contar con estos siervos de la Iglesia (familia ecclesiae) para mantener los edificios religiosos rurales y la celebración de los oficios a cambio del vestido y del alimento bajo la condición irrevocable de su fidelidad a los intereses de su patrona, la Iglesia, a la que se debían como siervos ${ }^{36}$.

Ante estas imposiciones tiene su lógica la abundancia de denuncias en los concilios de casos específicos de obispos y sacerdotes que hacían mal uso de los

${ }^{35}$ C. 49 IV Concilio de Toledo: Monachum aut paterna devotio aut propria professio facit; quidquid horum fuerit, alligatum tenebit: proinde eis ad mundum reverti intercludimus aditum, et omnem ad seculum interdicimus regressum (Vives 1963: 208).

${ }^{36}$ C. 12 Concilio de Mérida: Proinde instituit hoc sanctum synodum, ut omnes parrochitani presbyteres iusta ut in rebus sibi a Deo creditis sentiunt habere virtutem, de ecclesiae suae familia clericos sibi faciant, quos per bonam volumtatem ita nutriant ut officium sanctum digni peragant, et ad servitium suum aptos eos habeant. Hii etiam victum et vestitum dispansatione presbyteri merebuntur, et dominio et presbitero suo atque utilitati ecclesiae fideles esse debent (Vives 1963: 83). 
bienes eclesiásticos, así como del mal comportamiento de monjes y encargados de cuidar las iglesias (cs. 51, 52, 53 del IV de Toledo), o el de vírgenes y viudas consagradas por imposición paterna o señorial (c. 54) ${ }^{37}$. Incluso en este contexto de imposición por la fuerza podemos entender el abandono en que se encontraban algunos edificios eclesiásticos en muchos lugares a cargo de sacerdotes con poca dedicación o huídos por las dificultades de los tiempos y la misera de su condición. Así lo demuestran las quejas de los obispos reunidos en el Concilio de Tarragona a principios del siglo viI, recogidas en su canon 7 , sobre la falta de clero en las iglesias de su diócesis hasta el punto de que en las más pequeñas no se llegaban ni a encender las lámparas. Siguiendo con esta tónica el c. 5 del XVI Concilio de Toledo de 693 testimoniaba en época tan tardía el abandono de muchas iglesias por su pobreza y porque quienes tenían que atenderlas no lo hacían y, por esta razón, la Iglesia obligaba también a los obispos a reparar los edificios con las tercias entregadas por los fieles.

La situación pudo ser más dramática en los lugares donde la cristianización no fue promovida por las autoridades eclesiásticas, sino por la nobleza cristiana en sus dominios persiguiendo los mismos objetivos que sus antecesores paganos: por una parte dar posibilidad a los siervos y esclavos de sus predios de contar con un centro religioso cristiano que venía a suplir los antiguos edificios de culto paganos y, en segundo lugar, lucrarse mediante este hecho con las dádivas entregadas por las poblaciones al templo. Asi nacieron las denominadas en los textos "iglesias propias" en las que se solían depositar falsas reliquias de mártires para facilitar su culto y atraer a las poblaciones del entorno y de otros lugares que entregaban sus donativos y sus exvotos. Pero no siempre los señores utilizaban estos bienes para el mantenimiento de los templos y por ello el concilio de Sevilla II del año 619 legisló contra quienes cerraban y despojaban los monasterios situados en sus dominios (c. 10 y 11) mientras podemos ver, de una forma más explícita, en el c. 6 del II Concilio de Braga el porqué de muchas fundaciones y de su abandono al comprobar que muchos laicos lo hacían para recoger en ellas los tributos que se entregaban a Dios en su beneficio:

Se tuvo por bien que si alguno construye una iglesia, no por fe y devoción, sino por codicia y lucro, para repartirse lo que alli se reúna de las ofrendas del

${ }^{37}$ Melluso 2000: 236-265 señala en su trabajo como algunos papas trataron de impedir que los siervos entrasen en la iglesia aunque tuviera la libertad. Son los los servi confugientes ad ecclesiam y que fue una ley de Valentiniano III de 452, la que dio el visto bueno a los esclavos, originariii, inquilinio coloni para acceder ad clericale munus o escoger la via del monaterio para salir de su condicion. Por lo tanto una buena parte de la gente esclava de los grandes latifundios señoriales que acaba formando parte de la familia ecclesia, según ha demostrado esta autora, pasará a los monasterios y a formar parte de la nueva reorganización del territorio. 
De la villa a la ecclesia (I): Los documentos literarios sobre las transformaciones religiosas en la Hispania rural

pueblo a medias con los clérigos, alegando que él ha construido la iglesia en sus tierras, lo cual se afirma que se da hasta ahora en algunas partes, deberá pues en adelante observarse los siguiente: Que ningún obispo de su asentimiento a una propuesta tan abominable, atreviéndose a aconsagrar una basilica que no ha sido fundada para alcanzar la protección de los santos, sino más bien con fines tributarios ${ }^{38}$.

Un ejemplo más proviene de la Regula Fructuosi donde se denuncian este tipo de prácticas en los dominios privados que contaban con monasterios e iglesias consagradas a los mártires donde se recogían los hombres junto con sus mujeres, sus hijos, sus vecinos y sus siervos bajo la firmeza de juramento, hecho que la Iglesia consideraba perdición de las almas y subversión ${ }^{39}$. Por esta razón algunos concilios como el IX de Toledo (c. 2) lamenta que sea también la insolencia de algunos obispos la causante de la ruina de las iglesias y de que muchos fundadores privados cayesen por ello en la tristeza al ver el estado de los edificios que habían levantado con tanto amor, motivo por el que al parecer se permitía a los laicos mantenerlos aunque debían presentar a los obispos los rectores (entiéndase sacerdocio para el culto) para ser ordenados en dichas basílicas; aunque también el canon invalida ordenaciones dirigidas por los obispos sin haber sido aceptadas por los fundadores, lo que demuestra que la Iglesia era consciente de la necesidad de la implicación de los señores seglares en el compleja misión de cristianizar los territorios hispanos. A cambio no solo se apropiaba de las dádivas de los pobladores del lugar que pasaban a ser gestionadas por la iglesia local, también había un beneficio espiritual, pues los señores laicos comenzaron a enterrarse en el entorno sagrado de las basílicas o dentro de ellas, al amparo divino, en la forma denominada ad sanctos.

En definitiva, el paso de la villa a la villula es un fenómeno complejo, dilatado en el tiempo y en el que hay que tener en cuenta muy diversos factores. Pero es evidente también que el fenómeno de la cristianización de los antiguos lugares paganos es uno de los componentes principales de esta transfor-

${ }^{38}$ Placuit ut si quis basilicam non pro devotione fidei sed pro quaestu cupiditatis aedificat, ut quidquid ibidem oblatione populi colligitur medium cum clericis dividat, eo quod baselicam in terra sua ipse condiderit, quod in aliquibus locis usque modo dicitur fieri, hoc ergo de cetero observari debet, ut nullus episcoporum tam abominabili voto consentiat, ut baselicam quae non pro sanctorum patrocinio sed magis sub tributaria conditione est condita, audeat consecrare (Vives 1963).

${ }^{39}$ XXII “De primis conversorum": Solent enim nonnuli ob metum gehennae in suis sibi domibus monasteria componere et cum uxoribus filiis et servis atque vicinis cum sacramenti conditione in unum se copulare et in suis sibi ut diximus villis et nomine martyrum ecclesias consecrare et eas tale nomine monasteria nuncupare. Nos tamen haec non dicimus monasteria sed animarum perditionem et ecclesiae subversionem (Campo: 1971). 
mación. El cambio religioso e ideológico que supuso el auge del cristianismo y la persecución de los antiguos cultos, la desaparición de ciertos poderes y dominios paganos, la expropiación de sus bienes que benefició a la Iglesia y otros muchos factores tuvieron consecuencias socioeconómicas muy importantes que terminaron por afectar de manera muy sensible a las antiguas estructuras de la villa clásica. 
De la villa a la ecclesia (I): Los documentos literarios sobre las transformaciones religiosas en la Hispania rural

\section{Bibliografía}

ALVAR, J. (2014) Les chrétiens et les cultes à mystères dans les provinces hispaniques. Question de responsabilité et apport de l'archéologie. In: Baslez (dir.), Chrétiens persécuteurs. Destructions, exclusions, violences religieuses au IVe siècle. París, p. 361-394.

ÁLVAREZ SOLANO, F. E.; HURTADO BUSCATÓ, R.; RIVAS GARCÍA, O. (1999) La economía de Dios: la construcción de un santuario cristiano según los carmina natalicia de Paulino de Nola. Arys 2, p. 275-300.

ARCE, J. (1993) Los mosaicos como documentos para la historia de la Hispania tardía (siglos IV-v). AEspA 66, p. 265- 274.

BLÁZQUEZ MARTÍNEZ, J. M. (1981) Prisciliano introductor del ascetismo en VVAA Gallaecia. In: Primera reunión gallega de estudios clásicos. Santiago de Compostela, p. 210-236.

(1978) Problemas económicos y sociales en la Vida de Melania y la Joven y en la "Historia Lausiaca" de Palladio. Memorias de Historia Antigua, p. 103-123.

CABALLERO ZOREDA, L. (2000) La arquitectura denominada de época visigoda: ¿es realmente tardorromana o prerrománica?. In: Caballero Zoreda; Mateos Cruz (eds.) Visigodos y omeyas. Un debate entre la Tardoantigüedad y la Alta Edad Media. Anejos AespA 23, p. 207-247.

CAMACHO MACÍAS, A. (1988) El libro de las vidas de los santos padres de Mérida: opúsculo anónimo del siglo VII. Mérida, 1988.

CASTANYER MASOLIVER, P; TREMOLEDA TRILLA, J. (1997) La villa romana de Vilauba, Banyoles (prov. De Girona). MM 38, p.162-175.

CASTELLANOS. S. (1998) Poder social, aristocracias y hombre santo en la Hispania visigoda. La vita Aemiliani de Braulio de Zaragoza. Logroño.

(2004) La Hagiografía visigoda. Dominio social y proyección cultural, Logroño.

CODOÑER MERINO, C. (1972) El de viris illustribus de Ildefonso de Toledo. Estudio y edición crítica. Salamanca.

DÍAZ, P. C. (2001) Monasteries in a peripheral area: seventh-century Gallaecia. Topographies of holy power in sixth-century Gaul. In: De Jong; Theuws; Van Rhijn (Eds.) Topographies of Power in the Early Middle Ages. Leiden, Brill, p. 329-359.

ENJUTO SÁNCHEZ, B. (2000) Las disposiciones judiciales de Constantino y Juliano a propósito de las tierras de los templos paganos. Gerión 18, p. 407-423. 
ESCRIBANO PAÑO, V. (1988) Iglesia y estado en el certamen priscilianista. Causa ecclesiae y iudicum publicum. Zaragoza.

GELICHI, S. (2000) Ceramic production and distribution in the eaarly medieval mediterranean basin (seventh to thenth centuries ad): Between town and countryside. In: Brogiolo; Gauthier; Christie (eds.) Towns and their territories between Late Antiquity and the early Middle Ages. Leiden, Brill, p. $115-139$.

GODOY FERNÁNDEZ, C. (1995) Arqueología y liturgia: iglesias hispánicas (siglos IV al VIII). Barcelona.

GRUBER, J. (2006) 16 Jahre Ausonius-Forschung1989-2004, ein Überblick. Gymnasium 113 (4), p. 359-382.

GUERRA, A.; SCHATTNER, T.; FABIÃO, C.; ALMEIDA, R. (2005) São Miguel da Mota (Alandroal/Portugal) 2002 Bericht über die Ausgrabungen im Heiligtum des Endovellicus. MM 46, p.184-234.

HOURCADE, D. (2004) Géographie des villes fortifiées en Lusitanie romaine: tentative de définition de réseaux et de hyiérarchies urbaines. In: Gorges; Cerrillo; Nogales Basarrate (eds.) VMesa Redonda Internacional sobre Lusitania Romana: Las comunicaciones. Madrid, p. 223-253.

MELLUSO, M. (2000) Il tema di servi fugitivi in ecclesia in epoca giustinianea. Le Bullae Sanctae Sophiae. Arys 3, p. 236-265.

MARTIN GONZÁLEZ, S. (2011) From villae to villulae: settlement and social organization in Late Antique Hispanic countryside. In Hernández de la Fuente (Ed.) New perspectives on Late Antiquity. Newcastle upon Tyne.

ORFILA, M. (1993) Terra Sigillata Hispánica Tardía meridional. AEspA 66, p. $125-147$.

ORSELLI, M. (1999) Lidée chrétienne de la ville: quelques suggestions pour l'antiquité tardive et le Haut Moyen Age. In: Brogiolo; Ward-Perkins (Eds.) The idea and ideal of the town between Late Antiquity and the early Middle Ages. Leiden, Brill, p. 181-193.

SANZ SERRANO, R. (2000) Las relaciones de dependencia como factor de cristianización en la Península Ibérica: grupos de edad y cristianización. In: Myro; Alvar; Plácido (eds.) Las edades de la dependencia durante la Antigüedad. Madrid, p. 395-424.

(2003) Paganos, adivinos y magos. Análisis del cambio religioso en la Hispania Tardoantigua. Gerión (anejo viI).

(2007) Aristocracias paganas en Hispania Tardía (s. v-viI). In: Plácido; Moreno Arrastio; Ruiz Cabrero (Eds.) Necedad, sabiduría y verdad: el legado de Juan Cascajero. Gerión 25 (1), p. 443-480. 
De la villa a la ecclesia (I): Los documentos literarios sobre las transformaciones religiosas en la Hispania rural

(2009) Historia de los godos. Una epopeya histórica de Escandinavia a Toledo. Madrid. SANZ SERRANO, R.; RUIZ VÉLEZ, I. (2014) Vurovius y la cristianización de los espacios rurales en la península Ibérica. In: Mangas Manjarres; Novillo López (Eds.) Santuarios suburbanos y del territorio en las ciudades romanas. Madrid, p. 311-338.

SCHATTNER, T.; SUÁREZ OTERO, J.; KOCH, M. (2003) Monte do Facho 2003. Bericht über die Ausgrabungen im Heiligtum des Berobreus. $M M$ 46, p. 135-183.

VILELLA MASANA, J. (1990) La política religiosa del Imperio Romano y la cristiandad hispánica durante el siglo V. Antigüedad y Cristianismo VII, p. 385-389.

(1997) Priscilianismo gálico y política antipriscilianista durante el s. V.An. Tard. 5, p. $177-185$.

VIVES. J. (1.963) Concilios visigóticos e hispano-romanos. Madrid. 